\title{
In Vitro Release of Nicotine From Chewing Gum Formulations
}

\author{
Yamini Morjariaa ${ }^{1}$, William J Irwin ${ }^{1}$, Paul X Barnett ${ }^{2}$, Rick S Chan ${ }^{3}$, and \\ Barbara R Conway ${ }^{1,4}$
}

Email:conway@aston.ac.uk

\begin{abstract}
Release of nicotine from conventional gums and from gums made using a directly compressible gum base was studied using the European Pharmacopoeia apparatus for testing of medicated chewing gums. It was found that gum base and the method of preparation used in a formulation were important factors when controlling the release of drugs from chewing gum.
\end{abstract}

\section{Introduction}

$\mathrm{n}$ addition to its confectionery role, chewing gum

also has a proven value as a delivery vehicle for

pharmaceutical and nutraceutical ingredients (1). It can be taken discreetly without water and allows for local and systemic delivery. It can be employed for treatment of diseases of the oral cavity and throat, e.g. for caries prevention, or it can release drugs that can be absorbed through oral mucosa directly into the systemic circulation. In addition, drug that is not absorbed by the oral cavity membranes can be dissolved in the saliva before swallowing, thus leading to a more rapid onset of action.

The majority of chewing gum delivery systems today are manufactured using conventional gum processes. The gum base is softened or melted and placed in a kettle mixer where sweeteners, syrups, active ingredients and other excipients are added at a defined time. The gum is then sent to a series of rollers that form it into a thin, wide ribbon. During this process, a light coating of finely powdered sugar or sugar substitute is added to keep the gum from sticking and to enhance the flavour. Finally, the gum is cut to the desired size and cooled at a carefully controlled temperature and humidity.

As the heating process involved may limit the applicability of the process for formulation of thermally labile drugs, directly compressible, free-flowing powdered gums would be of use in extending the role of chewing gum in delivery systems. Pharmagum ${ }^{\circledR}$ is a compactable gum system that has been developed by SPI Pharma. Pharmagum ${ }^{\circledR}$ is a mixture of a polyol(s) and/or sugars with a gum base. These formulations can be compacted into a gum tablet using a conventional tablet press, thus enabling rapid and low-cost development of a gum delivery system.
The need for and value of in vitro drug release testing is well established for a range of dosage forms, however, standard dissolution apparatus is not suitable for monitoring release of drug from chewing gums as the action of chewing is essential, by providing a renewable surface for drug release after chew action. The release of substances from chewing gums during mastication can be studied by employing a panel of tasters and chew-out studies. During the mastication process, the medication contained within the gum product should be released into the saliva and is either absorbed through the oral mucosa or swallowed and absorbed through the gastrointestinal tract. The chewed gum can then be removed and analyzed for the residual drug substance while pharmacokinetics can be determined from blood samples. Disadvantages of chew-out studies include the requirement for human volunteers, lack of chew control and variations in the flow and composition of subjects' saliva.

A number of devices to mimic the chewing action have been reported (2,3, and 4). In 2000, the European Pharmacopoeia published a monograph describing a suitable apparatus for studying the in vitro release of drug substances from chewing gums (5). A study was carried out to explore differences in the release of nicotine from the directly compressible gum base compared with a conventional nicotine gum using the European Pharmacopoeia chewing apparatus described in the European Pharmacopoeia (5).

\section{Methods}

Two 4-mg Nicotine gum formulations (Table 1) were made using Pharmagum ${ }^{\circledR} \mathrm{M}$ and Pharmagum ${ }^{\circledR}$ S. Pharmagum ${ }^{\circledR}$ M has a $50 \%$ increase in gum base compared to Pharmagum ${ }^{\circledR} \mathrm{S}$. 
Table 1. Directly compressible nicotine gum formulations

\begin{tabular}{|lc|}
\hline Ingredient & $\%$ \\
\hline Pharmagum $^{\circledR}(\mathrm{S} / \mathrm{M})$ & 84.8 \\
\hline Nicotine Polacrilex & 2.2 \\
\hline Magnesium Stearate & 2.0 \\
\hline Sorbitol & 8.0 \\
\hline Sodium Carbonate & 3.0 \\
\hline
\end{tabular}

Table 2. Artificial Saliva Formulation

\begin{tabular}{|lc|}
\hline Components & Quantity (mmol L-1) \\
\hline $\mathrm{KH}_{2} \mathrm{PO}_{4}$ & 2.50 \\
\hline $\mathrm{Na}_{2} \mathrm{HPO}_{4}$ & 2.40 \\
\hline $\mathrm{KHCO}_{3}$ & 15.00 \\
\hline $\mathrm{NaCl}$ & 10.00 \\
\hline $\mathrm{MgCl}_{2}$ & 1.50 \\
\hline $\mathrm{CaCl}_{2}$ & 1.50 \\
\hline $\mathrm{Citric}$ Acid & 0.15 \\
\hline $\mathrm{pH}$ adjusted to 6.7 with $\mathrm{NaOH}$ or $\mathrm{HCl}$ \\
\hline
\end{tabular}

Pharmagum ${ }^{\circledR} \mathrm{S}$ consists primarily of gum base and sorbitol. Pharmagum ${ }^{\circledR} \mathrm{M}$ contains gum base, Mannitol and Isomalt (www.spipharma.com). The powder mix was compressed using a Manesty single-punch tablet machine. Nicorette ${ }^{\circledR}$ chewing gum (4 mg, batch/lot BH559A) was purchased and used as supplied.

The chewing machine consists of a temperature-controlled chewing chamber in which the gum piece is chewed by two electronically-controlled horizontal pistons driven by compressed air (Figure 1). The two pistons transmit twisting and pressing forces to the gum, while a third vertical piston, ("tongue") operates alternately to the two horizontal pistons to ensure that the gum stays in the appropriate position. The temperature of the chamber can be maintained at $37 \pm 0.5^{\circ} \mathrm{C}$ and the chew rate can be varied. Other adjustable settings include the volume of the medium, the distance between the jaws and the twisting movement. The European Pharmacopoeia recommends using $20 \mathrm{ml}$ of unspecified buffer (with a pH close to 6) in a chewing chamber of $40 \mathrm{ml}$ and a chew rate of 60 strokes per minute.

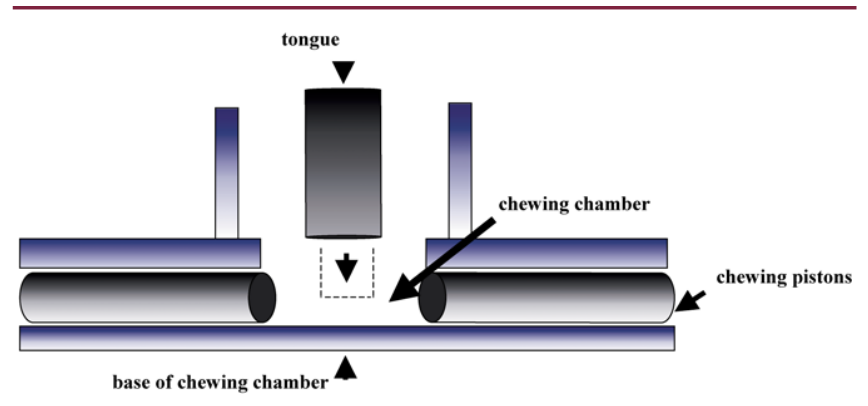

Figure 1. Schematic diagram of the chewing chamber of In vitro chewing apparatus used

The gums were placed in the chewing chamber with 40 $\mathrm{ml}$ of artificial saliva, see Table 2 (6). The temperature of the chewing chamber was set to $37 \pm 1^{\circ} \mathrm{C}$ with a chew rate of 60 chews/minute. The machine was run without chewing gum for the first two minutes, and then the buffer removed to ensure that any residues from the extensive washing and cleaning procedure were removed and to allow equilibration of chew rate and temperature. Release from the gum samples was then studied. Two- $\mathrm{mL}$ samples were taken at $0,5,10,15,20,25$ and 30 minutes and replaced with equal amounts of fresh artificial saliva. The samples were then immediately filtered though a $0.45 \mu \mathrm{m}$ filter and the nicotine levels determined using reversed-phase HPLC. A Waters Xterra RP-18 4.6 x150mm column was employed and the mobile phase consisted of $70 \%$ ammonium phosphate buffer ( $\mathrm{pH} 8.5): 30 \%$ acetonitrile. The injection volume was $20 \mu \mathrm{L}$, flow rate was $1 \mathrm{~mL} /$ minute and nicotine was detected at a wavelength of $260 \mathrm{~nm}$. These conditions resulted in a retention time of 3.4 minutes.

A CNS Farnell QTS 25 texture analyzer was used to study the texture of the gums. A $2 \mathrm{~mm}$ stainless steel probe was used to penetrate the gums at $30 \mathrm{~mm} / \mathrm{min}$ to a depth of $3 \mathrm{~mm}$. The load that encountered the probe was then plotted against time.

\section{Results and Discussion}

The dissolution curves for the release of nicotine (Figure 2) from the compressible formulations are similar $\left(f_{2}=82.4\right)$. Pharmagum ${ }^{\circledR} M$ and Pharmagum ${ }^{\circledR} S$ showed a faster release rate compared to the conventional gum $\left(f_{2}=36.6\right)$. An explanation for this can be proposed by examining the texture of the gums.

Pharmagum $^{\circledR} \mathrm{M}$ and Pharmagum ${ }^{\circledR} \mathrm{S}$ gums are similar to a tablet in appearance. Since Pharmagum ${ }^{\circledR} \mathrm{M}$ has $50 \%$ more gum base compared to Pharmagum ${ }^{\circledR} \mathrm{S}$ (www. spipharma.com), this should provide a more pleasant mouth feel and it was expected that this would result in a slower release of drug. However, this was not the case because both formulations crumbled when placed in the 


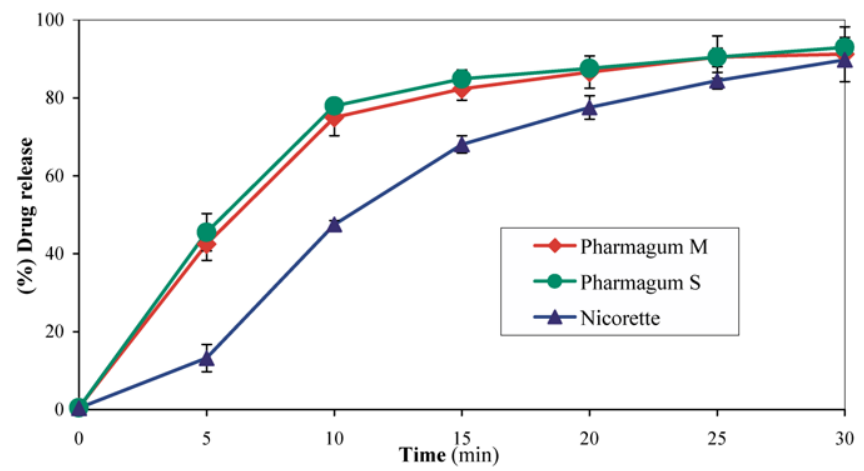

Figure 2. In vitro release of nicotine from compressible gum formulations and a commercial gum (Nicorette ${ }^{\circledR}$ 4mg) using the European Pharmacopoeia chewing gum apparatus.

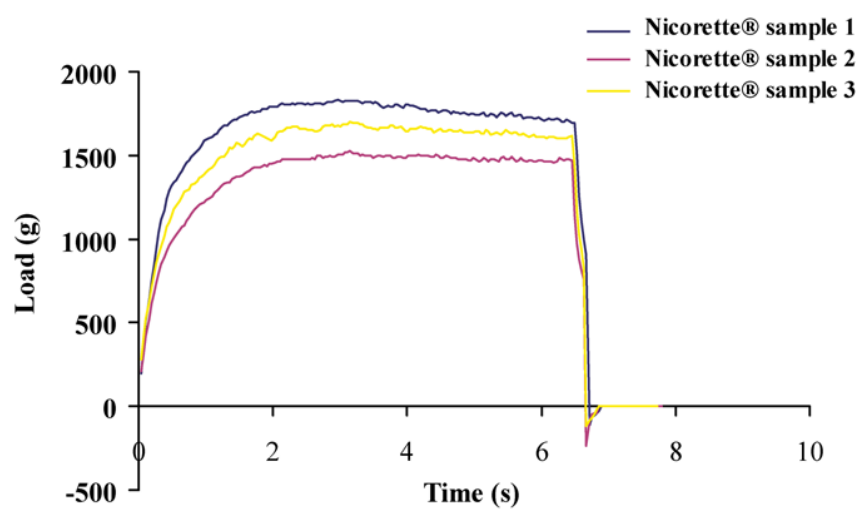

Figure 3.Texture profile of Nicorette ${ }^{\circledR}$ gum at $27^{\circ} \mathrm{C}$. (Each line indicates each gum sample analyzed and three samples were analyzed per formulation).

chewing machine. For patient acceptability, and in order to provide a controlled release of nicotine, the gum should remain intact during the chewing process. The texture of the gums under pressure (mimicking chewing action) can be studied using a texture analyzer.

Nicotine was released in a controlled manner from the conventional gum formulation (Figure 2). In vitro nicotine release from conventional gums has been shown to be comparable to reported chew-out studies (7). The gum was soft and remained intact when chewed in the chewing apparatus.

As the texture analyzer probe penetrated the conventional gum, a small constant force was needed to reach the desired depth. Once the desired depth was reached, on withdrawal a negative peak was observed, showing the adhesiveness of the gum (Figure 3). The gums formed using the compressible formulations are hard and crumble when pressure is applied (Figure 4). The peak height indicates the initial biting resistance or gum firmness, while the downward peak is related to tack or adhesion of the gum (1). Pharmagum ${ }^{\circledR} \mathrm{S}$, (mean hardness $21,783 \mathrm{~g}$ ), Pharmagum ${ }^{\circledR} \mathrm{M}$ (mean hardness $21,222 \mathrm{~g}$ ) are more than ten times the hardness of the conventional gums (mean hardness $1,684 \mathrm{~g}$ ). As the probe penetrated the

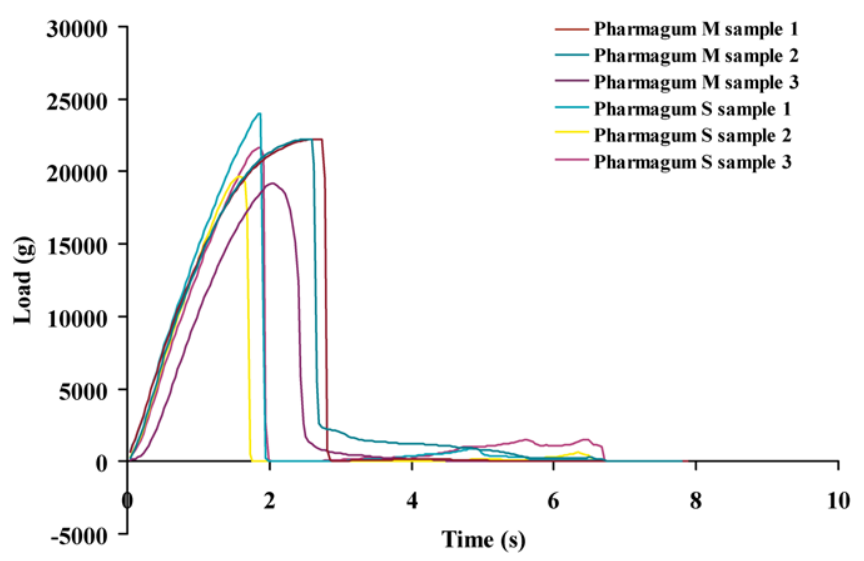

Figure 4. Texture profile of Pharmagum ${ }^{\circledR} M$ and Pharmagum ${ }^{\circledR} S$ at $27^{\circ} \mathrm{C}$. (Each line indicates each gum sample analyzed and three samples were analyzed per formulation).

Pharmagum ${ }^{\circledR} \mathrm{S}$ and $\mathrm{M}$ formulations, the gums crumbled like a tablet, hence, the sharp drop in the curve after 2 and 3 seconds respectively. This phenomenon was also observed in the chewing chamber of the chewing apparatus. The gum initially crumbles and then comes together to form a gum. The crumbling of the gum allows the nicotine to be released and provides a faster release rate compared to the conventional gums, which remain intact during the process. A possible explanation for the crumbling could be due to the formulation method of the gums. The gum particles are surrounded by various powdered excipients and are unable to flow together. When pressure is applied, the gum crumbles into the original particles. On wetting by saliva, the soluble excipients would wash away allowing the wetted gum particles to flow together.

\section{Conclusion}

Nicotine release from chewing gum formulations can be studied using the EP apparatus. The apparatus can be used as a quality control dissolution test and will prove valuable in the development of new chewing gum formulations.

\section{References}

1. WW Lee, "Chewing gum as a delivery vehicle for pharmaceutical and nutraceutical substances". Pharm Tech On-line, 2: 1-11, 2001.

2. LL Christrup and N Møeller, "Chewing gum as a drug delivery system". Arch Pharm Chem, Sci Ed, 14:30-36, 1986.

3. JN Rider, EL Brunson, WG Chambliss, RW Cleary, AH Hikal, PH Rider, LA Walker, CM Wyandt and AB Jones, "Development and evaluation of a novel dissolution apparatus for medicated chewing gum products". Pharm Res, 9: 255-260, 1992.

4. C Kvist, S-B Andersson, S Fors, B Wennergren and J Berglund, "Apparatus for studying in vitro release from 
medicated chewing gums". Int J Pharm, 189:57-65, 1999.

5. European Pharmacopoeia $4^{\text {th }}$ Edition-2002, General Chapter 2.9.25,"Chewing gum, Medicated, Drug Release From", pp 227-228, Directorate for the Quality of Medicines of the Council of Europe, Strasbourg, 2001.

6. S Parker, D Martin and M Braden, "Soft acrylic resin materials containing a polymerisable plasticiser II: Water absorption characteristics". Biomaterials, 20: 5560, 1999.

7. Y Mistry, WJ Irwin, BR Conway, P Barnett, T Grattan and RS Chan, "In vitro release of nicotine from commercially available nicotine gums using the European Pharmacopoeia apparatus." J Pharm Pharmacol 53S: 197, 2001.

\section{Acknowledgements}

This work was supported by the BBSRC and GlaxoSmithKline Consumer Healthcare. We are grateful to SPI Pharma for supplying the samples of Pharmagum . 